\title{
Orientation from open water to settlement habitats by coral reef fish: behavioral flexibility in the use of multiple reliable cues
}

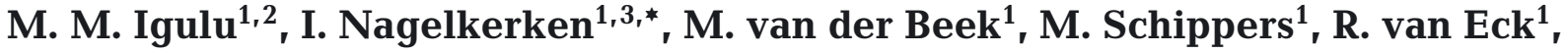 \\ Y. D. Mgaya ${ }^{4}$
}

${ }^{1}$ Radboud University Nijmegen, Institute for Water and Wetland Research, Department of Animal Ecology and Ecophysiology, PO Box 9010, 6500 GL Nijmegen, The Netherlands

${ }^{2}$ Tanzania Fisheries Research Institute, PO Box 9750, Dar es Salaam, Tanzania

${ }^{3}$ Southern Seas Ecology Laboratories, School of Earth and Environmental Sciences, DX 650 418, The University of Adelaide, Adelaide, South Australia 5005, Australia

${ }^{4}$ College of Natural and Applied Sciences, Department of Aquatic Science and Fisheries, University of Dar es Salaam, PO Box 60091, Dar es Salaam, Tanzania

\begin{abstract}
Most coastal marine organisms have a dispersive oceanic larval stage, during which they must be able to distinguish and respond to relevant environmental cues when settling into their first benthic habitat. Chemical stimuli emanating from settlement habitats and being dispersed by water plumes could enable long-distance navigation by larval reef fish, but we know little about the cues responsible and their interactive effects. In the present study, we tested this by conducting several ex situ choice experiments in which the response of the coral reef fish Lutjanus fulviflamma towards different chemical cues from coastal habitats was tested close to their settlement stage. Fish preferred seagrass habitat water over that from coral reef and mangrove habitats. Furthermore, fish were attracted to chemical cues from their own species (conspecifics) and other fish species, as well as vegetation of 4 different seagrass species, when offered in isolation (i.e. soaked in neutral water), but a strong response remained only towards cues from conspecifics and seagrass leaves when these cues were mixed with seagrass habitat water that naturally contains other cues. Hierarchical effects were observed as fish preferred chemical cues from seagrass leaves over those from conspecifics when both were offered at the same time. The importance of visual habitat cues only overruled that of chemical cues when it concerned preferred cues (i.e. seagrass as opposed to mangrove cues). Our findings indicate that pelagic fish and settlers possess the ability to use multiple reliable chemical cues to locate suitable early life stage habitats, although the importance of these cues is context-dependent. Nevertheless, this flexibility in choice behavior is probably an adaptive strategy to enhance fitness by increasing successful orientation towards preferred settlement habitats.
\end{abstract}

KEY WORDS: Sensory modalities $\cdot$ Mangrove $\cdot$ Seagrass $\cdot$ Coral reef $\cdot$ Chemical cues $\cdot$ Coral reef fish $\cdot$ Lutjanus fulviflamma

\section{INTRODUCTION}

The ability to navigate from one environment to another is an important part of life for terrestrial and aquatic animals. Many short-term activities, such as foraging, reproduction, and predator avoidance, require an organism to move in specific directions through a land- or seascape. The orientation for these movements involves the sensory modalities of an organism and the availability of relevant environ- 
mental cues. One of the common senses involved in orientation is that of smell (olfaction). Most animals are known to possess a well-developed olfactory system and the role of this sense has been widely documented. For example, birds are known to use chemical cues for navigation and orientation (Gagliardo et al. 2008, Holland et al. 2009), foraging (Nevitt 2008), and predator recognition (Amo et al. 2008). Honey bees can track the scent produced by flowering plants to trace potential food sources (Beekman 2005), while animals such as lizards can distinguish mates of different genotypes based on odor (Olsson et al. 2003).

In the aquatic environment, animals are exposed to an enormous diversity of cues that are mixed and dispersed by waves, currents, and tides. Fish, for example, can detect natural chemical cues at concentrations of parts per billion (Belanger et al. 2006) and therefore need to be able to separate relevant cues from high levels of background noise. Extracting useful information from these multiple cues is crucial to the survival of an individual. For example, hermit crabs can discriminate between a chemical cue from shells with a dead snail and that of dead conspecifics while looking for an empty shell, and this behavior has been proposed as a mechanism to reduce exposure time to predators and thus reduce mortality risk (Gherardi \& Atema 2005). Juvenile salmon imprint the chemical cue associated with their home stream before migrating offshore, and as adults they use their memory of this chemical signature to relocate their stream of birth for spawning (Dittman \& Quinn 1996). For settlement-stage larvae of marine organisms that are completing their oceanic life stage, the foremost important activity is to orientate to and locate an optimal benthic habitat. Chemical and auditory cues may play an important role for orientation during this process (Atema et al. 2002, Huijbers et al. 2012).

The decision-making process related to factors such as orientation, localization of food, and predator avoidance can involve single or multiple cues. When confronted with conflicting cues, an animal is expected to use the most reliable cue to increase its decision accuracy (Ward \& Mehner 2010). For instance, desert ants can rely on both visual and path integration cues to decide which landmarks are relevant for orientation (Wehner et al. 1996). However, in the case where visual and path integration information does not match, ants rely on path integration cues only (Wehner et al. 1996). Likewise, larvae of Apollo butterfly Parnassius apollo rely on olfaction cues over visual cues in locating host plants (Fred \&
Brommer 2010). Other studies indicate that the type of information an animal uses depends on the context or the immediate environmental conditions (Igulu et al. 2011), and an animal can use cues hierarchically according to local ecological conditions (Scapini et al. 1996). It is likely that for aquatic vertebrates, sound cues prevail over olfactory and visual cues when long distances are involved (Leis et al. 1996), primarily because sound travels long distances through water (Leis et al. 2002, Montgomery et al. 2006). Most research on orientation mechanisms in marine vertebrates, such as fishes, have focused on single sensory modalities (Basil et al. 2000, Gerlach et al. 2007, Huijbers et al. 2008) or multiple modalities using non-conflicting cues (Arvedlund et al. 1999, Brolund et al. 2003, Hale et al. 2009). However, little is known about the role of multimodality when it concerns conflicting cues.

The tropical coastal seascape is an intriguing environment to study how animals deal with conflicting cues to locate suitable benthic habitats. Fishes may use a suite of sensory cues for navigation, but their importance differs according to life phase as well as distance to the source (Kingsford et al. 2002). Various species of reef fish have larvae that navigate through multiple coastal ecosystems before settling (Nagelkerken 2009). For example, reef species that are associated with mangroves and seagrass beds during only their early life stage need to navigate as larvae from the open ocean, across coastal shelves that harbor coral reefs, towards bays or lagoons that harbor juvenile habitats (Pollen et al. 2007, Pollux et al. 2007). Potentially, larvae of such species consecutively use auditory, olfactory, and visual cues to navigate from the open ocean towards their settlement habitats (Huijbers et al. 2012). The settlement stage is usually short and lasts a few days at most (Milicich \& Doherty 1994), as larvae are extremely vulnerable to predation when they arrive near shore and have to pass through a 'wall of mouths' formed by coastal predators (Hamner et al. 1988, McCormick \& Kerrigan 1996, McCormick \& Holmes 2006). Fish larvae that settle in mangrove and seagrass habitats would greatly benefit from well-developed senses and use of reliable cues to locate more isolated inshore vegetated habitats. During their settlement stage, they may rely strongly on olfactory cues as these can disperse several 10 s to 100 s of meters from their source (Kingsford et al. 2002). Yet, the blend of chemical cues that larvae encounter is highly complex due to mixing of water bodies from diverse marine habitats. Our understanding of the cues that can be used by marine larvae to locate suitable habitats (Kingsford 
et al. 2002), and how they respond to conflicting cues during the critical settlement stage remains rudimentary. Clearly, there is a lack of complex studies using multiple and conflicting biotic cues to provide an understanding of how oceanic larvae manage to locate distant settlement habitat within an aquatic medium that is characterized by a complex mix of potential cues.

In the present study, we investigated the attraction of the early life stage of the tropical reef fish Lutjanus fulviflamma to a variety of chemical and visual cues to test the hypothesis that fish are most attracted to chemical cues from aquatic vegetation and conspecifics, as these are relatively reliable cues for orientation. We performed several choice experiments involving chemical cues from conspecifics, heterospecifics, different habitats, and different species of seagrass vegetation to tease apart which of the specific cues that are normally mixed within coastal waters elicit the strongest behavioral response by fish and could potentially be used for successful shoreward orientation during their critical early life stage. This insight will help us to better understand the behavioral flexibility that marine organisms with an oceanic life stage have to successfully locate settlement or juvenile habitats that can enhance their fitness.

\section{MATERIALS AND METHODS}

\section{Study area}

The study was carried out between February 2007 and March 2009 at Kunduchi, Dar es Salaam, Tanzania (Fig. 1). The Kunduchi Creek harbors mangrove forests with an estimated total surface area of 68.7 ha (Wang et al. 2003). The creek has a narrow entrance to the ocean $\sim 300 \mathrm{~m}$ wide, and is $2.2 \mathrm{~km}$ long from entrance to the origin. The area has an average tidal difference of $3.5 \mathrm{~m}$, and during low tides the mangrove-root area is completely drained. Besides rainwater, the Kunduchi Creek has no freshwater input. Ceriops tagal, Rhizophora mucronata, and Avicennia marina are the most dominant mangrove species on the landward side, followed by Sonneratia alba, Xylocarpus granatum, and Brugueira gymnorrhiza at the seaward side.

Off the Kunduchi coast (about $600 \mathrm{~m}$ ) lies a large seagrass bed extending from the spring low water mark to a depth of about $5 \mathrm{~m}$ offshore. Thalassia hemprichii and Thalassodendron ciliatum are the dominant seagrass species in this bed. Mbudya Island is located $3.5 \mathrm{~km}$ offshore and is fringed by shallow

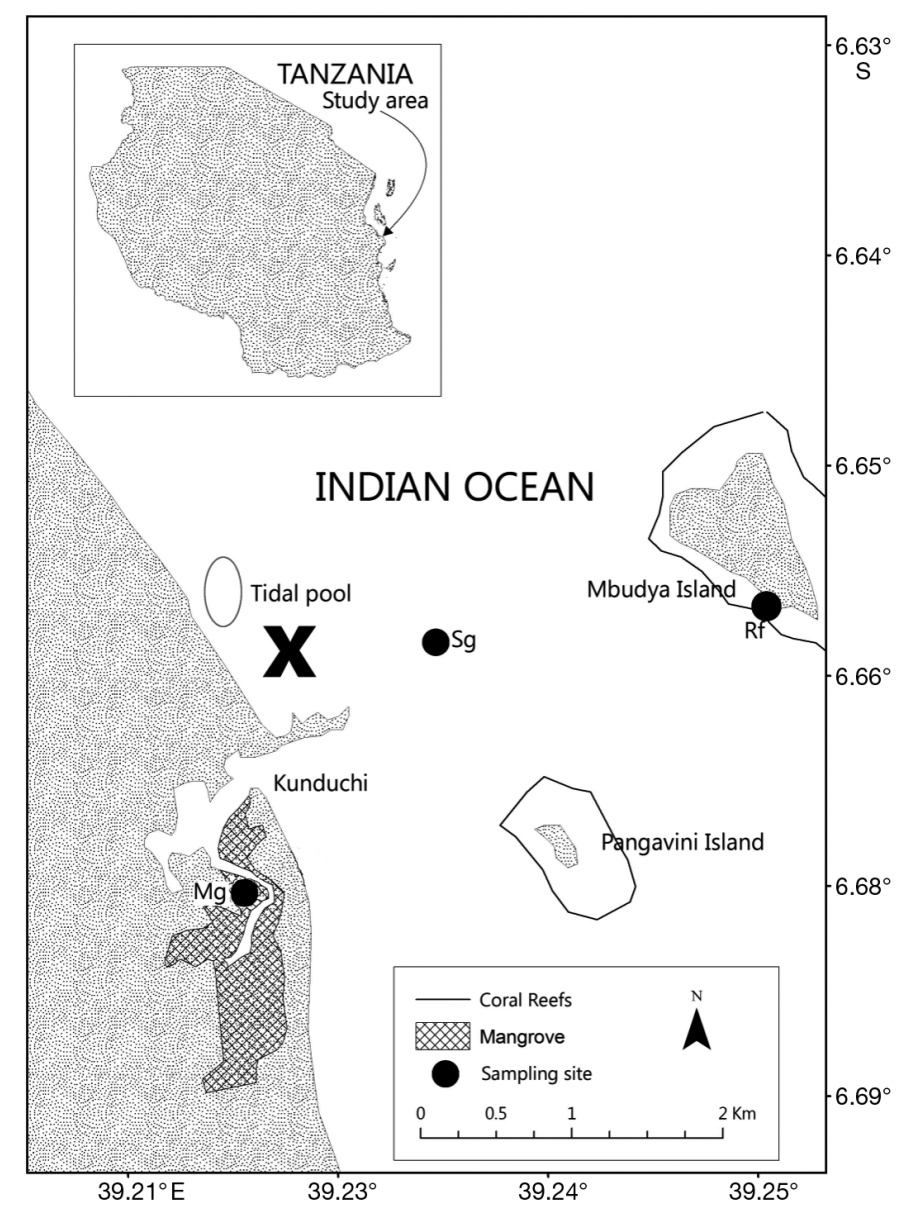

Fig. 1. Sampling locations for collection of habitat water types from mangroves $(\mathrm{Mg})$, seagrass beds $(\mathrm{Sg})$, and coral reefs (Rf), and for collection of 'neutral' seawater from a barren sand flat $(\mathbf{X})$

(3 to $10 \mathrm{~m}$ depth) coral reefs. Reefs are dominated by the coral species Acropora formosa and Montipora aequituberculata.

\section{Fish collection and choice chamber design}

Our focal fish species was the Dory snapper Lutjanus fulviflamma, as this common fish occurs in multiple coastal habitats (Lugendo et al. 2007, Kimirei et al. 2011). This largely zoobenthivorous fish species typically occurs as juveniles in seagrass beds and mangroves, which provide shelter (Igulu et al. 2011) and feeding areas (Lugendo et al. 2006), whereas the adults are predominantly found on coral reefs (Kimirei et al. 2011). Experimental fish were caught daily in a tidal pool at an average depth of $0.4 \mathrm{~m}$ (Fig. 1) using a beach seine net. The tidal pool consisted of a soft-bottom substratum without vegetation 
and was isolated from other habitat cues, such as that from mangrove, seagrass, or coral reef. On a daily basis, we sampled the same pool to catch all new individuals that had recruited into the tidal pool on the previous day and night. The average total length of the fish was $27 \pm 6 \mathrm{~mm}$ (mean $\pm 1 \mathrm{SD}, \mathrm{N}=438$ ). Settlement size of most lutjanids is estimated to be about 11 to $18 \mathrm{~mm}$ total length (Brogan 1996, Clarke et al. 1997), so either L. fulviflamma settles at larger sizes at our study area or our specimens had settled elsewhere and moved to the tidal pools afterwards. All fish that were collected on the same day from the same school were carefully transferred to the laboratory within 10 min after capture and kept in an aquarium $(1.2 \times 0.4 \times 0.4 \mathrm{~m}, \mathrm{l} \times \mathrm{w} \times \mathrm{h})$ with fresh seawater from a storage tank at ambient temperature, together with an air bubbler and 3 to 4 rocks for shelter. All fish were kept overnight at a maximum density of 30 individuals per aquarium before the experiments to acclimatize to laboratory conditions, and were not fed.

We used 2 types of choice chambers for testing chemical cues: (1) a dual-choice rectangular aquarium for all control experiments and experiments with chemical cues from habitats, conspecifics, and heterospecifics; and (2) a multiple-choice square aquarium for experiments comparing chemical cues from 4 different species of seagrass. The rectangular aquarium
(Fig. 2a) was divided into 3 compartments: a large central compartment, separated by 2 vertical glass plates from 2 smaller side compartments. The central compartment was visually divided into left, middle, and right zones. The 2 glass plates that separated the central compartment from the side compartments were painted black and each plate had a parallel row of 5 holes of $6 \mathrm{~mm}$ diameter all located at a height of $5 \mathrm{~cm}$ from the bottom glass plate. Water from the side compartments flowed into the central compartment through these holes. The aquarium was completely painted black on the sides to exclude any external visual cues. The top was left open to allow light to enter.

In each corner of the square aquarium, a $0.5 \times$ $0.4 \mathrm{~m}(\mathrm{l} \times \mathrm{w})$ transparent glass plate with a parallel row of 5 holes $(6 \mathrm{~mm}$ diameter, $5 \mathrm{~cm}$ above the bottom) was attached to the 2 nearest sides of the aquarium, creating 4 equally sized side compartments and a large central compartment (Fig. 2b). The square aquarium was surrounded by a wooden box to block any external visual cues from outside.

To test for responses towards chemical and visual cues simultaneously, we adapted the rectangular aquarium by attaching a small glass box of $0.4 \times$ $0.15 \times 0.3 \mathrm{~m}(1 \times \mathrm{w} \times \mathrm{h})$ to each of the 2 side panels that separated the central from the side compartments (Fig. 2c). The small glass boxes were attached at the top of the aquarium and were used to hold
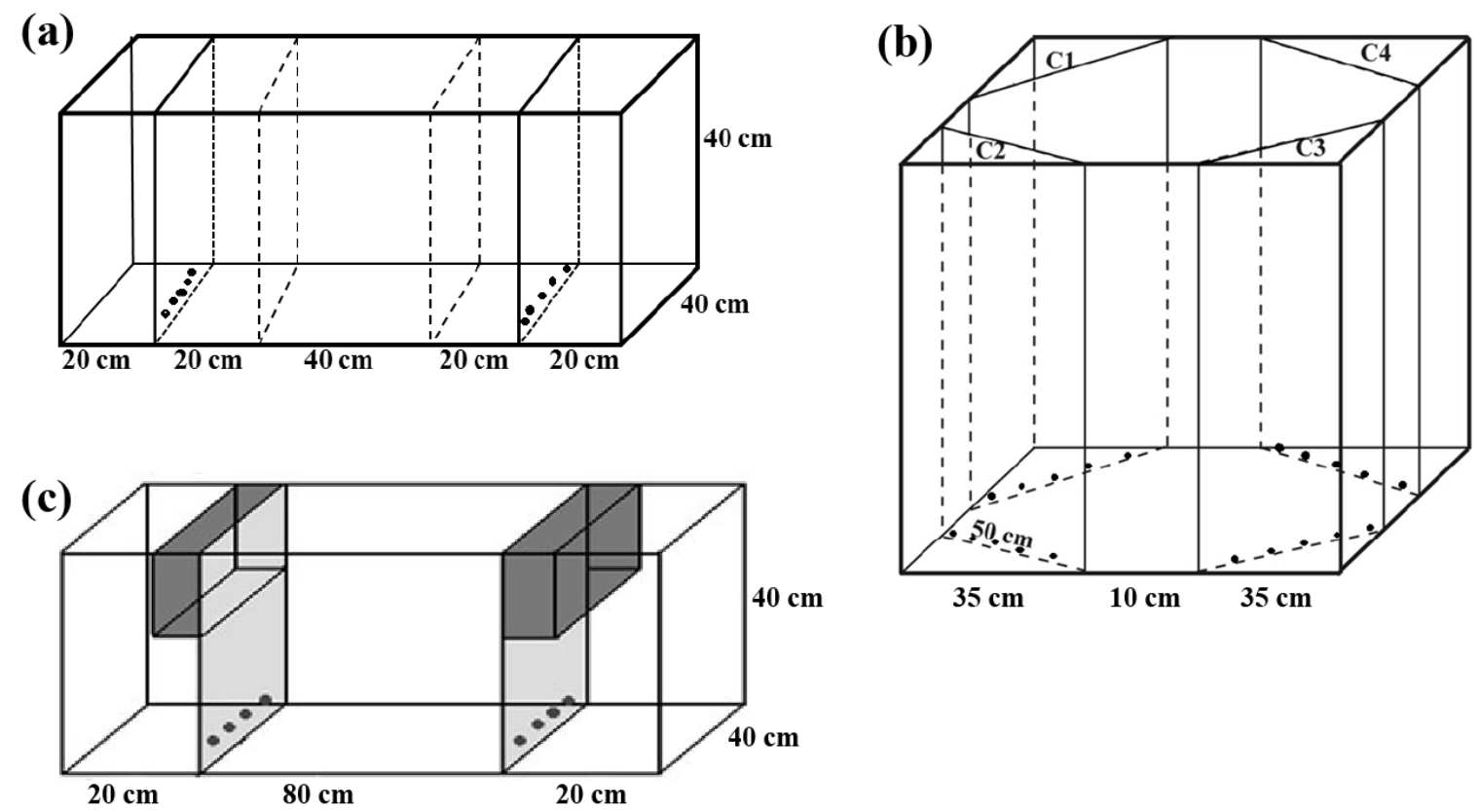

Fig. 2. The experimental aquaria. (a) A dual-choice aquarium with left and right side compartments for testing fish response to chemical cues. The 2 dashed squares visually divide the central compartment into a left, middle, and right part to determine the position of the fish during the experiment. (b) A multiple-choice aquarium with 4 side compartments (C1 to C4) for testing fish response to 4 different chemical cues. (c) A dual-choice aquarium adjusted for testing fish responses to chemical and visual cues at the same time 
mangrove or seagrass vegetation to create visual habitat cues.

All side compartments of the 3 aquarium types were connected with plastic tubes to $10 \mathrm{l}$ supply buckets. We first used colored dye to determine the optimal flow rate and to study how cue water mixed and flowed within the central compartment of the aquarium. A flow rate of approx. $200 \mathrm{ml} \mathrm{min}^{-1}$ was used, which resulted in water plumes from opposite sides reaching the centre of the aquarium after $15 \mathrm{~min}$. During the experiment, there was no drainage from the central compartment and the flow rate was regularly checked.

Experiments were conducted between 10:00 and 16:00 $\mathrm{h}$ in a separate room in the laboratory with minimal noise from outside. The experimental room had large glass windows and light was relatively evenly distributed. The dual-choice aquarium was always aligned in an east-west direction to avoid possible interference from the Earth's electromagnetic field (Kirschvink \& Gould 1981). Each fish was only used once in the experiments to avoid pseudo-replication.

At the time of the experiments, no animal ethics committee existed in Tanzania, therefore there was no formal evaluation process. However, details of the experiments were presented to the Tanzania Fisheries Research Institute scientific committee. Furthermore, animal handling followed the guidelines of the Association for the Study of Animal Behaviour and the Animal Behaviour Society. All fishes were returned to the sea after the experiments and care was taken to minimize injuries or death of any individuals.

\section{Water collection and chemical cue preparation}

'Neutral' seawater for filling the aquaria was pumped daily from a large barren sand flat $300 \mathrm{~m}$ offshore during incoming tide (Fig. 1). The water was stored in the laboratory in 2 dark plastic tanks of $1500 \mathrm{l}$ containing air bubblers and was left to settle overnight before the experiments.

Seagrass bed $(\mathrm{Sg})$ and mangrove $(\mathrm{Mg})$ habitat water was collected on the same day as the experiments and stored in the laboratory for $1 \mathrm{~h}$ before the experiments. To ensure that the collected water had circulated in the respective habitat for as long as possible, we collected water during the last hour of the outgoing tide. Mangrove water was collected at the mouth of the creek, while seagrass bed water was collected at the offshore seagrass bed (Fig. 1). Reef water (Rf) was collected at the reefs of Mbudya Island by SCUBA divers, as close as possible to the corals, using buckets that were closed underwater before being brought up to the surface. Owing to logistic constraints, water from the reef was collected on the afternoon preceding the experiments.

To create chemical cues from conspecifics (Lutjanus fulviflamma, Lf) and heterospecific fishes (Siganus sutor, $\mathrm{Ss}$, and Terapon jarbua, $\mathrm{Tj}$ ), 5 individuals of the same size as the test fish were kept inside a $10 \mathrm{l}$ bucket containing neutral water from the storage tank for $1 \mathrm{~h}$ before the experiments. During the experiments, the conspecifics or heterospecifics were left inside the supply buckets. Species of heterospecifics that co-occurred in the habitats where L. fulviflamma was found were chosen (Kruitwagen et al. 2010).

To create chemical cues for the different species of seagrass (Halophila ovalis, Syringodium isoetifolium, Thalassia hemprichii, and Thalassodendron ciliatum - $\mathrm{Ho}, \mathrm{Si}, \mathrm{Th}$, and $\mathrm{Tc}$, respectively), $65 \mathrm{~g}$ of seagrass leaves from each species with attached epiphytes and part of the stem were soaked inside a $10 \mathrm{l} \mathrm{bucket}$ containing neutral water from the storage tank for $1 \mathrm{~h}$ before the experiments. After $1 \mathrm{~h}$, this water was transferred to the buckets that supplied cue water to the aquaria.

\section{Experimental protocol}

Water temperature and salinity were measured both in the field and in the laboratory during the course of the experiments using a HACH sensION156 meter. No significant difference was found between laboratory and field values for salinity or temperature for any of the habitats tested (Table 1). Before each experiment, all compartments of the aquarium were filled with neutral seawater from the storage tanks to a height of $20 \mathrm{~cm}$ and dry beach sand was used as a substratum. The aquarium used to test chemical and visual cues simultaneously (Fig. 2c) was filled with seawater to just below the top so that fish could see the compartments with habitat structures. In all experiments and all aquarium designs, the inflow of cue water into the side compartments started 3 min before we introduced the fish into the test aquarium, to build up the cue concentration.

A single test fish was carefully introduced into the middle compartment using a small plastic can filled with seawater, and allowed to acclimatize for $2 \mathrm{~min}$; thereafter, the time the fish spent in each area of the central compartment was recorded. For the dualchoice aquarium, this was the left, right, or middle part of the central compartment, whereas for the multiple choice aquarium, this was within $10 \mathrm{~cm}$ of any of 
Table 1. Mean values $( \pm \mathrm{SE})$ of water temperature and salinity, measured in the laboratory and the field during the course of the experiments. Values within brackets indicate the number of replicates. Differences were tested with a $t$-test

\begin{tabular}{|lcccccc|}
\hline & \multicolumn{2}{c}{ Temperature $\left({ }^{\circ} \mathrm{C}\right)$} & p-value & Salinity & Field \\
\hline Lab & Field & & Lab & $33.6 \pm 0.2(14)$ & $33.1 \pm 0.5(15)$ & 0.549 \\
Seef & $27.7 \pm 0.3(14)$ & $27.4 \pm 0.3(15)$ & 0.421 & $33.2 \pm 0.1(53)$ & $33.8 \pm 0.2(32)$ & 0.164 \\
Mangrass & $27.6 \pm 0.2(53)$ & $27.5 \pm 0.2(32)$ & 0.774 & $33.6 \pm 0.3(23)$ & $33.2 \pm 0.1(30)$ & 0.131 \\
\hline
\end{tabular}

the 4 glass plates through which cues were released (Fig. 2). The observer was positioned at the middle part of the central compartment, $\sim 50 \mathrm{~cm}$ away from the long side of the aquarium and refrained from any movement during the observation period. Each experiment lasted $15 \mathrm{~min}$. To counteract a potential effect of differential light distribution and any other unforeseeable effects in the laboratory, the dual-choice aquarium was turned $180^{\circ}$ and the square aquarium was turned $90^{\circ}$ after every 3 replicates, while the choice of cue inflow was interchanged in the dual-choice aquarium after each replicate and randomly re-assigned to the 4 side compartments in the square aquarium after each replicate. After each experiment with a single fish, the aquarium was emptied and carefully cleaned inside with ethanol and left to dry before the next replicate, so as to avoid introducing chemical cues from the previous conspecifics or water type.

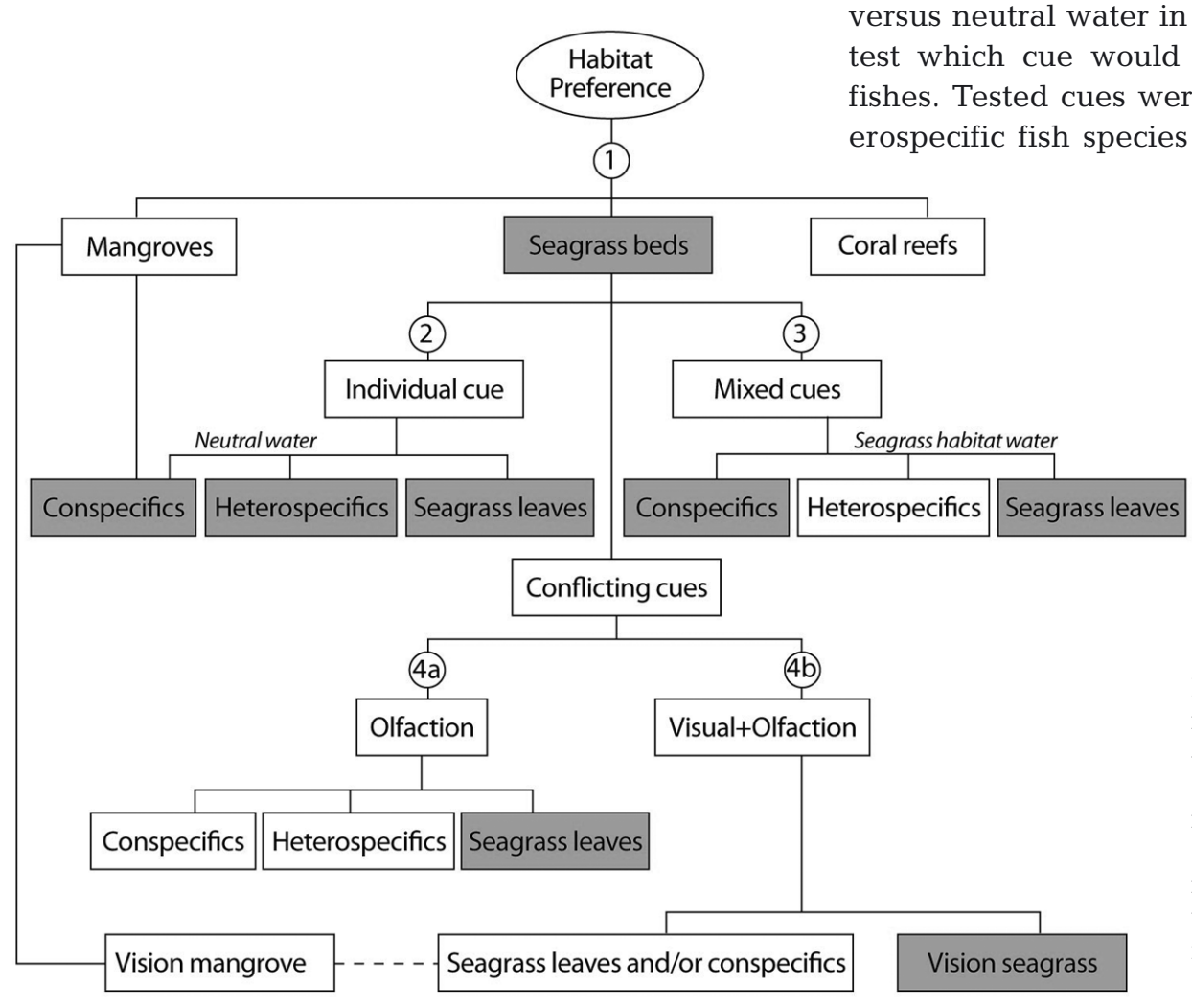

\section{Experiments performed}

We first performed control experiments to test the effects of aquarium sides and water flow in the dualchoice aquarium. For the former, non-flowing neutral water was present in all 3 compartments, while for the latter neutral water flowed from both side compartments into the central compartment.

In the first cue experiment, we first established which chemical habitat cues fish were attracted to using the dual-choice aquarium (Fig. 3). Combinations of coral reef, mangrove, and seagrass habitat water collected in situ were offered. As fish preferred seagrass habitat water, we continued with an experiment to determine the importance of isolated chemical cues that are normally mixed in natural seagrass habitat water.

In the second experiment, we offered cue water versus neutral water in the dual-choice aquarium to test which cue would evoke a response from the fishes. Tested cues were that of conspecifics, 2 heterospecific fish species (Siganus sutor and Terapon
Fig. 3. Flow chart for the experiments performed. Numbers (1 to 4) indicate the sequence of the experiments; grey filled boxes indicate predominant cue preference by the test fish. Dashed line indicates the preference test between visual cues of mangrove roots and chemical cues from seagrass leaves 
jarbua), and one species of seagrass vegetation (Thalassia hemprichii). Both conspecifics and heterospecifics were collected on the same day of the experiments and they had had no previous contact with the tested fishes. As multiple species of seagrass are found in seagrass beds, we also tested the flexibility in attraction to seagrass by simultaneously offering cues from 4 different species of seagrass (Halophila ovalis, Syringodium isoetifolium, Thalassia hemprichii, and Thalassodendron ciliatum) in the multiple-choice aquarium.

In the third experiment, we tested whether fish still responded to the individually tested cues when they were offered in a mixture with preferred habitat water (i.e. seagrass habitat water). The rationale behind this was that fish may respond to a specific cue in isolation as no other choice is available at that time, but when this cue is mixed with preferred habitat water containing other relevant cues as well, the importance of that cue may be lost. For this purpose, preferred habitat water versus a mixture of preferred habitat water and a single cue (i.e. that of conspecifics, the heterospecific fish Siganus sutor, or seagrass leaves) was offered in the dual-choice aquarium.

In the fourth experiment, we tested the effect of conflicting cues in the 2 dual-choice aquaria. First, we offered conflicting chemical cues: a mixture of preferred conspecific cues and non-preferred mangrove habitat versus a mixture of non-preferred heterospecific cues and preferred seagrass habitat. As a control, we also offered non-conflicting chemical cues in a similar set-up: a mixture of preferred conspecific and preferred seagrass habitat cues versus a mixture of non-preferred heterospecific and preferred seagrass habitat cues. We then tested the fish choice behavior when the 2 most preferred isolated chemical cues were offered at the same time: seagrass leaves versus conspecifics. To this end we soaked ( $1 \mathrm{~h}$ ) fish and seagrass to create different cue strengths: we offered the test fish neutral water in which $65 \mathrm{~g}$ of seagrass leaves versus $\sim 80 \mathrm{~g}$ of conspecifics (5 individuals) had been soaked, as well as neutral water in which $65 \mathrm{~g}$ of seagrass leaves versus $\sim 230 \mathrm{~g}$ of conspecifics (15 individuals) had been soaked. Finally, in the adjusted dual-choice aquaria, we tested the effect of conflicting visual and chemical cues by offering a choice between non-preferred visual habitat cues (mangrove roots) and preferred chemical habitat cues (seagrass), as well as a choice between preferred visual habitat cues (seagrass leaves) and preferred chemical cues (conspecifics held in seagrass habitat water), based on the fact that visual cues mostly override chemical cues when present at the same time (Ward \& Mehner 2010). For these experiments, one side of the aquarium provided a visual cue (either 10 Thalassia hemprichii [seagrass] plants or 15 Sonneratia alba [mangrove] roots in the glass box) but no chemical cue (only flowing neutral water), whereas the other side provided no visual cue (empty glass box) but a chemical cue (either seagrass habitat water alone or conspecifics soaked in seagrass habitat water).

\section{Statistical analysis}

Statistical tests were performed with SPSS 16.0 for Windows. For each experiment, the percent time spent at each cue was first calculated (based on a total of $15 \mathrm{~min}$ ). The middle part of the aquarium represented lack of attraction to either of the 2 simultaneous cues offered and was therefore not incorporated into the statistical tests (Tolimieri et al. 2004). Time spent at each cue and in the middle compartment always totaled $100 \%$. Normality of the data was confirmed with a Shapiro-Wilks test and homogeneity of variances was confirmed with a Levene's test. To test for significant differences within experiments, pairedsamples $t$-tests for dual-choice experiments (Peterson $\&$ Renaud 1989) or repeated-measures ANOVA (multiple-choice experiments) were performed. For the repeated-measures ANOVA, a Mauchly's test was used to determine whether the variances between groups were equal. In cases where this assumption was not met, a Greenhouse-Geisser correction was used to produce a valid F-ratio. Bonferroni post-hoc pairwise comparisons were used to further detect differences between groups. To test for differences among independent experiments, a Student's $t$-test (2 comparisons) or a 1-way ANOVA (multiple comparisons) was used. For all tests, the statistical significance level was set at $\mathrm{p}=0.05$.

\section{RESULTS}

\section{Control experiments}

The control experiments showed that fish had no side preference for the test aquarium when no cues were offered in either non-flowing or flowing water, but in the latter case fish were more attracted to the 2 sides of the aquarium from which water flowed (Fig. A1 in Appendix 1). Test fish spent significantly less time in the middle part of the central compartment of the aquarium when there was water 

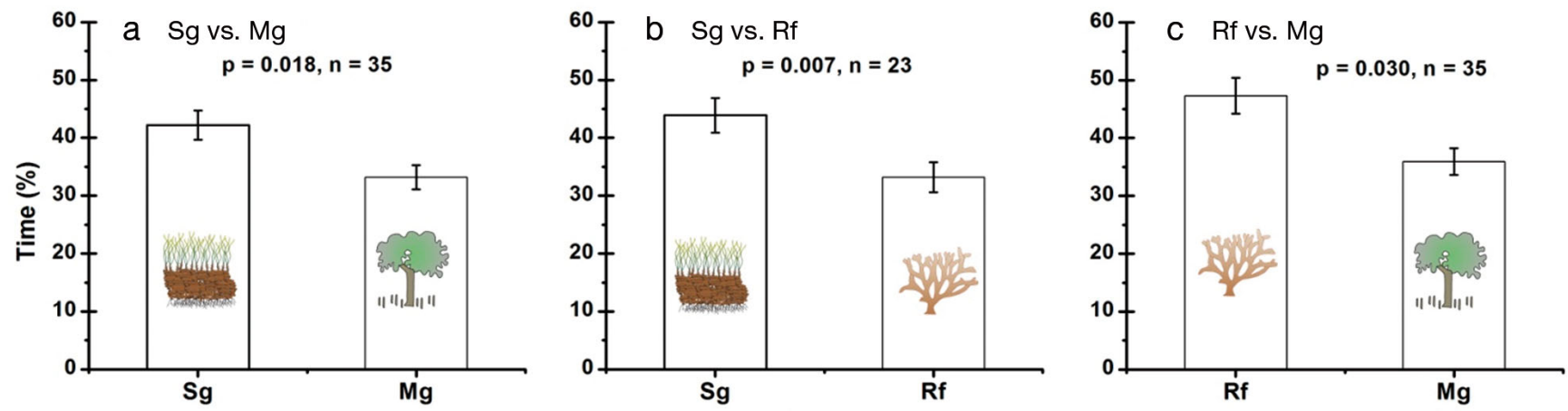

Fig. 4. Mean percentage $( \pm \mathrm{SE})$ of time fish spent at each side of the dual-choice aquarium supplied with 2 types of water: Mg $=$ mangrove, $\mathrm{Sg}=$ seagrass, and $\mathrm{Rf}=$ reef habitat water collected in situ. $\mathrm{p}$-values show results of paired $t$-tests and $\mathrm{n}=\mathrm{number}$ of replicates. Image credit for Figs. 4 to 7: Catherine Collier, Diana Kleine, Tracey Saxby, Dieter Tracey, Christine Thurber, Joanna Woerner, IAN Image Library (http://ian.um-ces.edu/imagelibrary)

flow from the sides as opposed to no water flow (i.e. $43 \pm 7.3 \%$ versus $62 \pm 3.2 \%$ [Mean $\pm \mathrm{SE}]$, respectively; $t$-test, $t=-3.150, \mathrm{df}=19$ and $\mathrm{p}=0.006)$.

\section{Experiment 1: Do fish discriminate among different habitat water cues?}

The test fish were clearly able to distinguish among different habitat water types and showed a significant preference for water from seagrass beds over that from the mangroves and the reef (Fig. 4 \& Table A1 in Appendix 1). For consecutive experiments, seagrass habitat water was therefore used as a preferred habitat. Fishes further preferred water from the reef over that from the mangroves. The percentage time spent in the middle part of the compartment was low (14 to $19 \%$ ) and did not differ among experiments (1-way ANOVA, df $=2$, $F=0.417$ and $\mathrm{p}=0.662$ ). Furthermore, for the seagrass-mangrove experiment, 12 of the test fish spent more than $50 \%$ of the observation time at the seagrass cue side compared with 3 that spent more than $50 \%$ of their time at the mangrove cue side. Likewise, 17 versus 5 and 13 versus 8 fish spent more than $50 \%$ of their time at the respective aquarium sides for the reef-mangrove and seagrass-reef experiments, respectively.

\section{Experiment 2: Do fish respond to potentially reliable cues in isolation?}

Test fish were significantly attracted to chemical cues from conspecifics, 2 heterospecific fish species, and seagrass vegetation when offered in isolation (Fig. 5a-d). The degree of attraction to these isolated cues was similar (1-way ANOVA, df $=3, F=2.332$ and $p=0.083$ ) and fish spent 47 to $58 \%$ of their time at the aquarium side where a cue was offered. Percentage of time spent in the middle part of the compartment was low (18 to $28 \%$ ) and did not differ among the 4 experiments (1-way ANOVA, $\mathrm{df}=3, F=$ 1.440 and $\mathrm{p}=0.240$ ). Furthermore, test fish were equally attracted to chemical cues from different seagrass species (Fig. 5e).

\section{Experiment 3: Do fish still respond to preferred cues when mixed with natural habitat water?}

Test fish still showed a significant attraction to chemical cues from conspecifics and from seagrass vegetation when these were mixed with seagrass habitat water that naturally contains an aroma of chemical cues (Fig. 6a,c), but this was not the case for a mixture of seagrass habitat water and cues from a heterospecific fish species (Fig. 6b). The percentage of time spent in the middle part of the compartment was low (15 to $33 \%$ ), but differed among the 3 experiments (1-way ANOVA, df $=2, F=7.305$ and $p=0.001$ ) with time spent in the middle being higher for the experiment in Fig. 6a (Bonferroni posthoc test, $\mathrm{p}<0.001$ ).

\section{Experiment 4: How do fish respond to conflicting cues?}

Test fish did not show a significant difference in choice when conflicting cues were offered at both sides of the aquarium, viz. a mixture of chemical cues from preferred conspecifics and non-preferred mangrove habitat versus a mixture of cues from preferred seagrass bed habitat and non-preferred heterospecifics (Fig. 7a). Removal of one of the con- 

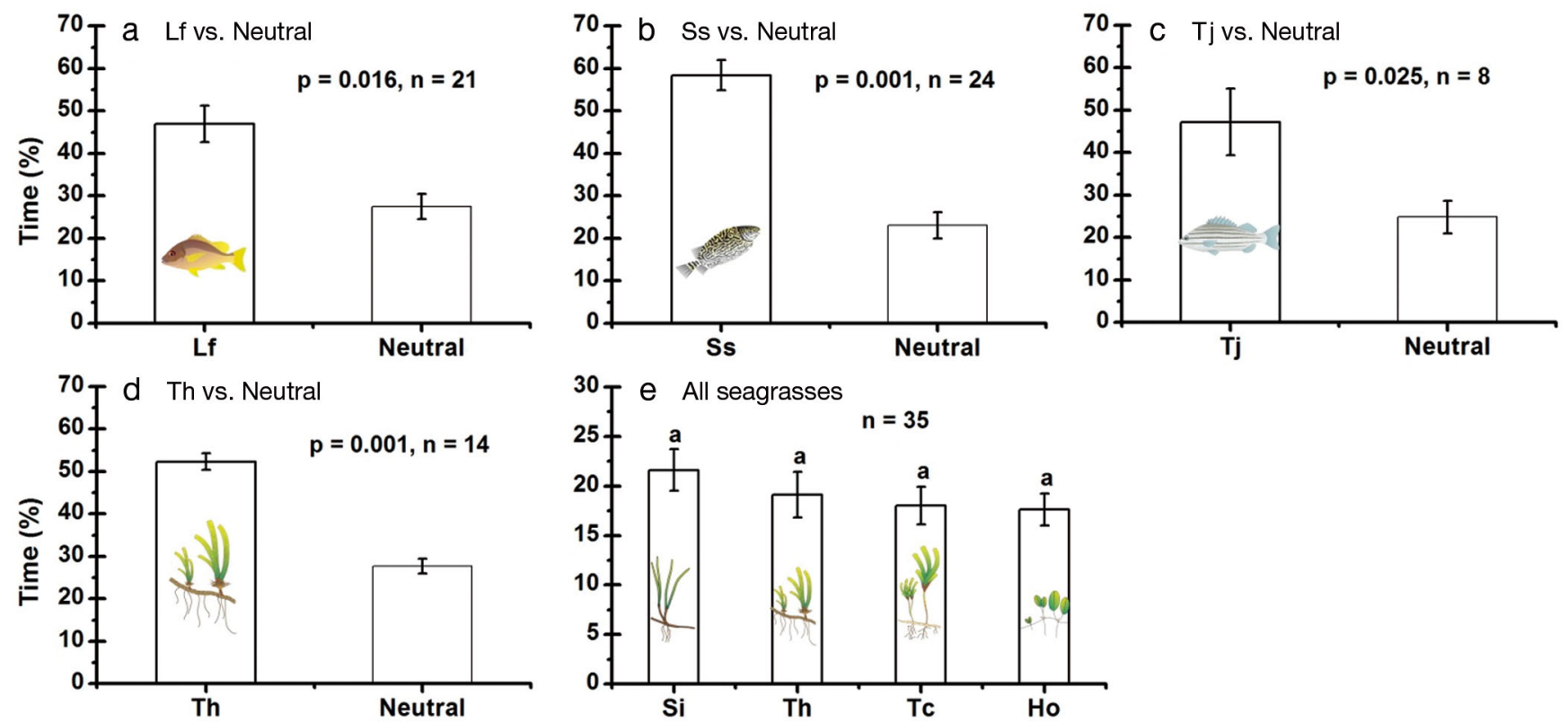

Fig. 5. (a-d) Mean percentage ( \pm SE) of time fish spent at each side of the dual-choice aquarium when offered water with a cue at one side and neutral water at the opposite side. Chemical cues offered in the water were: Lf = conspecifics Lutjanus fulviflamma, $\mathrm{Ss}=$ heterospecifics Siganus sutor, $\mathrm{Tj}=$ heterospecifics Terapon jarbua, and $\mathrm{Th}=$ seagrass vegetation Thalassia hemprichii. Neutral $=$ control water from the storage tank. $\mathrm{p}$-values show results of paired $t$-tests and $\mathrm{n}=$ number of replicates. (e) Mean percentage $( \pm \mathrm{SE}$ ) of time fish spent at each corner of the multiple-choice aquarium supplied with cues from 4 different seagrass species: $\mathrm{Si}=$ Syringodium isoetifolium, $\mathrm{Th}=$ Thalassia hemprichii, $\mathrm{Tc}=$ Thalassodendron ciliatum, Ho $=$ Halophila ovalis. Same letter above error bars indicates lack of a significant difference among seagrass species (repeated measure ANOVA, $F=0.672, \mathrm{df}=3,32$ and $\mathrm{p}=0.570$ )

flicting cues (i.e. mangrove habitat water) from the above experiment resulted in a significantly higher attraction to chemical cues from conspecifics over heterospecifics when mixed in seagrass habitat water (Fig. 7b). When the 2 preferred chemical cues (conspecifics and seagrass) were offered at the same time, test fish showed a significantly higher preference for cues from seagrass leaves (Fig. 7c). This preference was persistent, even when a 3.5 times higher weight of conspecifics versus seagrass leaves was soaked and offered (Fig. 7d). Finally, fish showed an equal attraction to visual cues from non-preferred mangrove roots and chemical cues from preferred seagrass habitat water (Fig. 8a), but were significantly more attracted to visual seagrass cues than chemical seagrass cues even though the latter also contained chemical cues from conspecifics (Fig. 8b).
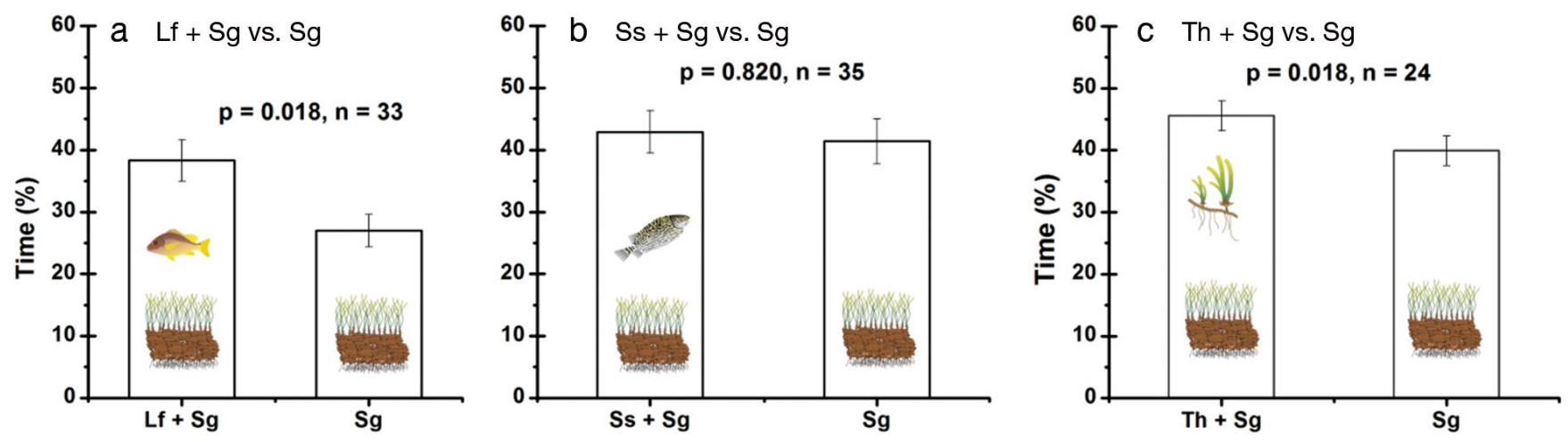

Fig. 6. Mean percentage $( \pm \mathrm{SE})$ of time fish spent at each side of the dual-choice aquarium when offered seagrass habitat water (Sg) at one side, and seagrass habitat water with an additional chemical cue from either conspecifics, heterospecifics, or seagrass vegetation at the other side of the aquarium. Chemical cues offered were: (a) $\mathrm{Lf}+\mathrm{Sg}=$ seagrass habitat water in which conspecifics (Lutjanus fulviflamma, Lf) had been kept; (b) Ss + Sg = seagrass habitat water in which heterospecifics (Siganus sutor, Ss) had been kept; (c) $\mathrm{Th}+\mathrm{Sg}=$ seagrass habitat water in which seagrass leaves (Thalassia hemprichii, Th) had been soaked. p-values show results of paired $t$-tests and $\mathrm{n}=$ number of replicates 

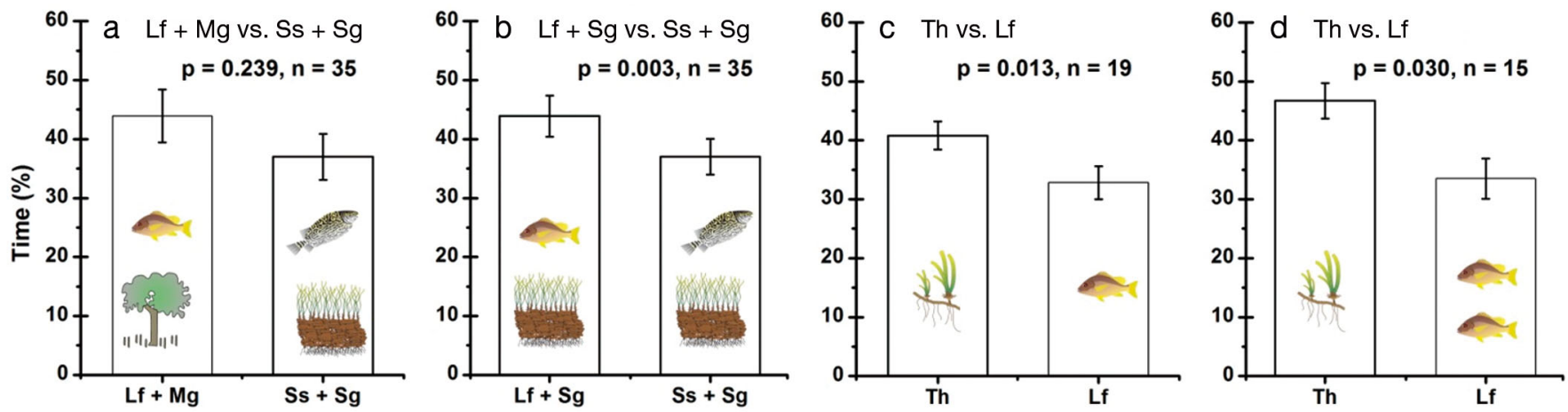

Fig. 7. Mean percentage $( \pm \mathrm{SE})$ of time fish spent at each side of the dual-choice aquarium when offered different cues at both sides. (a) Lf + Mg = mangrove habitat water (Mg) in which conspecifics (Lutjanus fulviflamma, Lf) had been kept versus Ss + $\mathrm{Sg}$ = seagrass bed water (Sg) in which heterospecifics (Siganus sutor, Ss) had been kept. (b) Lf + Sg = seagrass habitat water in which conspecifics had been kept versus $\mathrm{Ss}+\mathrm{Sg}=\mathrm{as}$ in (a). (c) Neutral water in which $65 \mathrm{~g}$ of seagrass leaves had been soaked versus neutral water in which 5 conspecifics $(\sim 80 \mathrm{~g})$ had been kept. (d) Neutral water in which $65 \mathrm{~g}$ of seagrass leaves had been soaked versus neutral water in which 15 conspecifics had been kept $(\sim 230 \mathrm{~g})$. p-values show results of paired $t$-tests and $\mathrm{n}=$ number of replicates
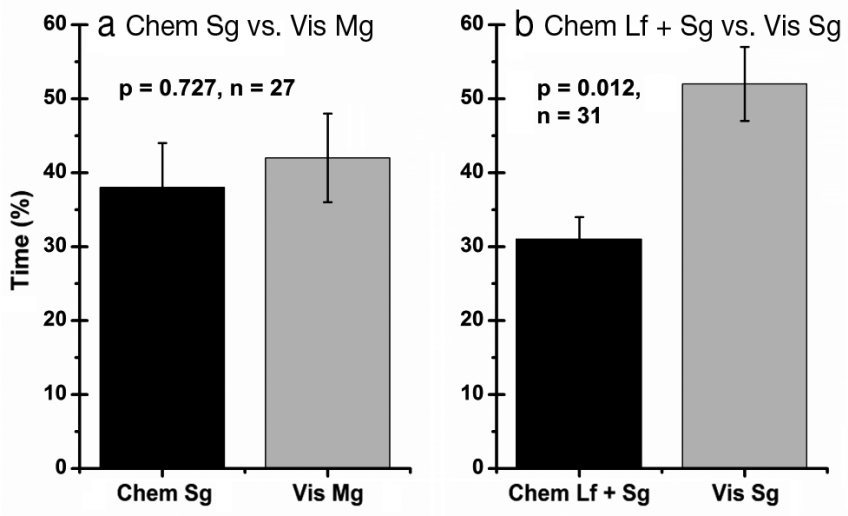

Fig. 8. Mean percentage $( \pm \mathrm{SE})$ of time fish spent at each side of the adjusted dual-choice aquarium when offered a chemical cue at one side and a visual cue at the other side of the aquarium. (a) Vis $\mathrm{Mg}=$ visual cue from mangrove roots Sonneratia alba versus Chem $\mathrm{Sg}=$ chemical cue from seagrass habitat water. (b) Vis $\mathrm{Sg}=$ visual cue from seagrass vegetation Thalassia hemprichii versus Chem $\mathrm{Lf}+\mathrm{Sg}=$ chemical cues from seagrass habitat water $(\mathrm{Sg})$ in which conspecifics (Lutjanus fulviflamma, Lf) had been kept. p-values show results of paired $t$-tests and $\mathrm{n}=$ number of replicates

\section{DISCUSSION}

The present study shows that fish are clearly able to distinguish between chemical cues of various types of aquatic plants and animals during their early life stage. Fishes preferred mixed water bodies from seagrass beds over that from coral reefs and mangroves, which equates their distribution across coastal settlement habitats (Kimirei et al. 2011). Furthermore, juvenile Lutjanus fulviflamma are also visually more attracted to seagrass leaves than to mangrove roots or corals (Igulu et al. 2011). Given the strong olfactory preference for water from seagrass beds, we conclude that larvae and recent settlers of coral reef fish species that live in seagrass habitats before moving to the reef are likely to possess adaptive behavior enabling them to identify specific chemical cues emanated by vegetated habitats that can be used for orientation towards these habitats. This behavior could serve as a mechanism to maximize successful settlement or recruitment to preferred habitat (Kingsford et al. 2002). It has been shown that seagrass beds have lower predation risk compared with coral reefs (Grol et al. 2011, Kimirei et al. 2013). Adaptive behavior that leads to successful orientation and recruitment to seagrass beds can thus ultimately lead to increased survival, which is critical for population maintenance. However, localizing and navigating towards isolated inshore habitats such as seagrass beds that are located beyond the reef might increase the short-term mortality risk associated with an increased search time while residing in the open water column (Zollner \& Lima 2005). Nevertheless, at the population level, such a trade-off between an increased predation risk in the short-term and a long-term increase in fitness might be a beneficial strategy. The results further show presence of a behavioral trait that enables fishes to successfully locate inshore coastal habitats under different scenarios and provides a certain degree of insurance against misjudgment of habitat quality that could result in population declines (Weldon \& Haddad 2005).

While it is known that some fishes are attracted to the smell of mixed water bodies from seagrass habitats (Arvedlund \& Takemura 2006, Huijbers et al. 2012), studies typically did not evaluate which potential cues of animals or plants living in seagrass ecosystems could be responsible for this. The mecha- 
nisms to achieve successful orientation to early life stage habitats are still poorly understood, especially for fishes that recruit to non-reef environments. The present study is one of the first to show that multiple biotic cues of preferred recruitment habitat elicit a response, but that the response is strongly contextdependent. When offered in isolation, fish showed a positive response to 3 different and relatively reliable chemical cues that are usually found mixed within natural seagrass habitat water: (1) conspecific cues, which could indicate suitable living areas where individuals of the same species have survived (Sweatman 1988, Lecchini et al. 2007, Igulu et al. 2011), but also serves as a cue to locate own species or school with to reduce predation risk from other species (Huijbers et al. 2011); (2) heterospecific cues, which indicate potentially suitable living areas where juveniles of other fish species have survived (Igulu et al. 2011); and (3) seagrass leaf cues, which indicate nearby presence of suitable vegetated habitats that provide shelter (Arvedlund \& Takemura 2006). Fish were still attracted to 2 of these preferred chemical cues (conspecifics and seagrass leaves) when they were offered in a mixture with natural seagrass habitat water, showing that these cues provided additional information compared with the mixed aroma of seagrass habitat water alone.

Essential information gained from conspecific and seagrass leaf cues include habitat suitability, as strong chemical cues of conspecifics in seagrass habitat water indicate presence of nearby seagrass habitat harboring significant numbers of successfully settled fish, and directional information, as an increasing concentration of seagrass vegetation cues provides a mechanism to navigate while swimming in a turbulent environment (Finelli et al. 1999). Both types of information are important, as settling in a habitat that has proven to be suitable for other fish or quickly locating a settlement habitat (i.e. with shorter search time and thus lower predation risk while moving in the open water column) are important determinants for survival. In this light, the observed lack of an additive effect of heterospecific cues mixed with seagrass habitat water may be explained by the fact that heterospecific cues probably do not provide any beneficial information about habitat suitability.

Conspecific chemical cues seem relevant to tropical marine fishes independent of the first benthic habitat that they occupy. While a few studies have reported the use of chemical cues from conspecifics for settling fish larvae, the main focus has been on juvenile fish that settle directly onto coral reefs. For example, larvae of the damselfish Dascyllus aruanus settled on coral with chemical cues from resident adult conspecifics, while heterospecifics avoided settling on coral heads with chemical cues from adult D. aruanus (Sweatman 1988). This evidence points to the active selection of chemical cues from conspecifics, which can aid in locating other fish to reduce predation risk. Likewise, larvae of the damselfish Chromis viridis responded positively to conspecific chemical cues in coral reefs over those in reefs unoccupied by conspecifics species (Lecchini et al. 2005). Studies have shown that marine fish larvae are attracted to specific organic compounds produced by conspecifics (Lecchini et al. 2005), such as fatty acids, amino acids, carbohydrates, simple proteins, glycoproteins, and phospholipids (see review by Hara 1975). Amino acids are especially attractive olfactory stimuli and may play an important role in chemical signaling (Hara 1973, Shoji et al. 2003). The importance of conspecific chemical cues is underpinned by the results of the present study, as they seem to play a role in vegetated low-risk habitats as well.

In the present study, the identity of seagrass vegetation did not play a role in their attractiveness to fishes. Studies have suggested that chemical compounds produced by aquatic vegetation include tannins and phenolic substances, and can act as chemoattractants to settling recruits (Arnold \& Targett 2002). Fish did not show a significant preference for the chemical cues of a particular seagrass species. Instead, they were equally attracted to chemical cues from all types of seagrass vegetation offered, as on average fish spent $76 \%$ of their time at a side compartment containing seagrass cues and only $24 \%$ in the central part of the aquarium. This finding suggests that settling fish are not confined to the odor of a specific species of seagrass, which is an important finding, as it shows flexibility in choice behavior related to locating settlement habitats. Relying on cues of a single seagrass species would reduce survival chances in cases where a habitat harboring preferred seagrass species is absent or difficult to locate (Jenkins \& Sutherland 1997).

Various chemical cues probably play a different role at different spatial scales. Water plumes containing chemical cues from lagoon habitats can be transported over long distances offshore by wind and ocean currents (Booth et al. 2000, Atema et al. 2002). In the absence of visual habitat cues at larger distances offshore, a preference for seagrass habitat water over coral reef or mangrove habitat water can act as a coarse, but reliable cue for offshore pelagic larvae to navigate towards coastal habitats from the 
open ocean. Based on experiments using auditory, olfactory, and visual cues, Huijbers et al. (2012) proposed that larvae of fishes that are associated with mangroves and seagrass as juveniles use reef sounds for long-distance navigation from the open ocean towards coastal reefs, switch to olfactory cues closer to shore, and then use visual cues when settling to the benthos. Based on our findings we suggest that when pelagic larvae are approaching coastal environments, seagrass leaves and resident conspecifics could provide important chemical cues at smaller spatial scales that would enable larvae to more accurately navigate towards specific profitable areas within lagoons or estuaries during the final stage of settlement or directly afterwards.

Hierarchical effects existed among preferred chemical cues. While chemical cues from conspecifics and seagrass vegetation both provide useful information for orientation and elicited a strong response when offered in isolation, fishes were more strongly attracted to seagrass-leaf cues than those of conspecifics when both were offered at the same time. This preference remained even when the concentration of conspecific cues was increased by soaking a 3.5-fold higher biomass of conspecifics than seagrass vegetation in the experimental water, showing a clear hierarchy between 2 attractive cues. Chemical cues from seagrass leaves are probably more reliable, as seagrass vegetation persists throughout the year in tropical areas, while conspecifics may not always be present within this habitat. Alternatively, the need to find suitable habitat may have priority over investigation of conspecific odors. This preference for seagrass cues might reflect innate behavior that has been genetically selected for through higher survival rates of fish with this trait, and could be a similar mechanism as that of, for example, reef fish that may use chemical cues from terrestrial forest vegetation to navigate towards coastal environments (Dixson et al. 2008). Preferential selection for this trait could result from higher survival chances of fish that locate and settle in seagrass habitat (Grol et al. 2011) irrespective of the presence of conspecifics, compared with those that are more attracted to conspecifics irrespective of seagrass presence.

The fact that seagrass water (when mixed with heterospecific cues) was not preferred over conspecific cues (when mixed with mangrove habitat water) also shows that choice preference is context-dependent, for example, when conflicting cues are present. Replacing the non-preferred mangrove habitat cues with seagrass habitat cues solved this dilemma and fish were more attracted to a mixture of 2 preferred cues (seagrass habitat and conspecifics) than one (seagrass habitat). This directly ties in to the observed fish response for 2 different sensory modalities. While visual cues mostly overrule olfactory cues at smaller spatial scales (Ward \& Mehner 2010), fishes showed equal preference for visual cues of mangrove roots as for chemical cues of seagrass habitat water. This provided a conflicting situation where a choice needed to be made between immediate availability of shelter, but from a habitat other than the preferred settlement habitat (Igulu et al. 2011), versus chemical cues from the preferred settlement habitat, which may or may not have guided them successfully to that habitat. The common overruling effect of visual over olfactory cues only became evident when fishes were offered visual cues of preferred seagrass settlement habitat versus chemical cues from a mixture of preferred seagrass habitat and conspecifics and favored the former. While a continued search for superior habitat (i.e. one providing seagrass structure as well as conspecifics) could increase fitness, it may also decrease immediate survival due to increased search time and associated predation risk (Toonen \& Tyre 2007). Hence, during the early life stages when mortality risk is extremely high and there is only a short time span to make decisions related to choice of first benthic habitat, there seems to be a tradeoff where direct visual presence of structure from preferred settlement habitat but lacking conspecifics to provide safety in numbers is preferred over chemical cues that can only potentially guide fish to preferred habitat already successfully occupied by conspecifics. Finally, while not tested here, food items may also provide essential olfactory and visual cues that aid in the selection of settlement habitat. Early juveniles of Lutjanus fulviflamma are known to be plankton feeders and settling in areas with high zooplankton densities would be beneficial as well.

In the present study, we used recently settled fish as we were unable to collect larvae from the open ocean. We sampled the same tidal pool on a daily basis and therefore were able to collect fish that had recruited into the tidal pool during the previous afternoon and night. Although fish may potentially not be considered naïve once they have settled, it is unlikely that fish lose their attraction to preferred chemical cues directly after settlement. Various studies have used recent settlers where larvae were not available (Dixson et al. 2008, Huijbers et al. 2008) and have shown that recently settled fish showed the same cue preference even if they had been collected from different settlement habitats (Grol et al. 2011, Huijbers et al. 2011). One study even showed that habitat 
preference (for mangrove) persisted up to the adult stage for any size of settled fish collected from reef, seagrass, or rubble habitat (Huijbers et al. 2011). We are therefore confident that the choice behavior of the fishes tested in the present study represents a true response of settlement-stage fishes.

\section{CONCLUSIONS}

The present study demonstrated that fishes are attracted to multiple biotic cues associated with their settlement habitat during their early life stage. Chemical cues from seagrass leaves as well as those from conspecifics are likely to play an important role in the orientation towards profitable habitat during or directly after settlement. Both cues can be used independently, while the preference for seagrass vegetation species is indiscriminative. This shows that settlers do not rely on a single source of information, although the specific response to each of these cues is context-dependent and hierarchically structured. Likewise, visual cues only overruled chemical cues when they provided information about preferred habitats. The multimodality in choice behavior and flexibility in cue use may constitute a good adaptive strategy to increase successful orientation towards difficult-to-target early life stage habitats that provide benefits in terms of increased survival and fitness. The apparent importance of seagrass chemical cues for successful establishment of some reef fishes argues for the conservation of seagrass ecosystems and their water quality, especially in the light of their rapidly decreasing surface areas worldwide (Waycott et al. 2009).

Acknowledgements. This work was supported by the Faculty of Science of the Radboud University Nijmegen; I.N. was funded through a VIDI grant from the Netherlands Organisation for Scientific Research (NWO); M.v.d.B. was supported by the Schure-Beijerinck-Popping Fonds. Special thanks go to Mmanga and Richard for logistic support in the field and to the Department of Aquatic Sciences and Fisheries of the University of Dar es Salaam for office and lab space.

\section{LITERATURE CITED}

Amo L, Galvan I, Tomas G, Sanz JJ (2008) Predator odour recognition and avoidance in a songbird. Funct Ecol 22: 289-293

Arnold TM, Targett NM (2002) Marine tannins: the importance of a mechanistic framework for predicting ecological roles. J Chem Ecol 28:1919-1934

Arvedlund M, Takemura A (2006) The importance of chem- ical environmental cues for juvenile Lethrinus nebulosus Forsskål (Lethrinidae, Teleostei) when settling into their first benthic habitat. J Exp Mar Biol Ecol 338:112-122

> Arvedlund M, McCormick MI, Fautin DG, Bildsoe M (1999) Host recognition and possible imprinting in the anemonefish Amphiprion melanopus (Pisces: Pomacentridae). Mar Ecol Prog Ser 188:207-218

- Atema J, Kingsford MJ, Gerlach G (2002) Larval reef fish could use odour for detection, retention and orientation to reefs. Mar Ecol Prog Ser 241:151-160

Basil JA, Hanlon RT, Sheikh SI, Atema J (2000) Threedimensional odor tracking by Nautilus pompilius. J Exp Biol 203:1409-1414

Beekman M (2005) How long will honey bees (Apis mellifera L.) be stimulated by scent to revisit past-profitable forage sites? J Comp Physiol A 191:1115-1120

Belanger RM, Corkum LD, Li WM, Zielinski BS (2006) Olfactory sensory input increases gill ventilation in male round gobies (Neogobius melanostomus) during exposure to steroids. Comp Biochem Physiol A 144:196-202

Booth DJ, Kingsford MJ, Doherty PJ, Beretta GA (2000) Recruitment of damselfishes in One Tree Island lagoon: persistent interannual spatial patterns. Mar Ecol Prog Ser 202:219-230

Brogan MW (1996) Larvae of the eastern Pacific snapper Hoplopagrus guntheri (Teleostei: Lutjanidae). Bull Mar Sci 58:329-343

> Brolund TM, Nielsen LE, Arvedlund M (2003) Do juvenile Amphiprion ocellaris (Pisces: Pomacentridae) recognize conspecifics by chemical or visual cues? J Mar Biol Assoc UK 83:1127-1136

Clarke ME, Domeier ML, Laroche WA (1997) Development of larvae and juveniles of the mutton snapper (Lutjanus analis), lane snapper (Lutjanus synagris) and yellowtail snapper (Lutjanus chrysurus). Bull Mar Sci 61:511-537

Dittman A, Quinn T (1996) Homing in Pacific salmon: mechanisms and ecological basis. J Exp Biol 199:83-91

Dixson DL, Jones GP, Munday PL, Planes S and others (2008) Coral reef fish smell leaves to find island homes. Proc R Soc Lond B Biol Sci 275:2831-2839

Finelli CM, Pentcheff ND, Zimmer-Faust RK, Wethey DS (1999) Odor transport in turbulent flows: constraints on animal navigation. Limnol Oceanogr 44:1056-1071

Fred MS, Brommer JE (2010) Olfaction and vision in host plant location by Parnassius apollo larvae: consequences for survival and dynamics. Anim Behav 79:313-320

> Gagliardo A, Ioale P, Savini M, Wild M (2008) Navigational abilities of homing pigeons deprived of olfactory or trigeminally mediated magnetic information when young. J Exp Biol 211:2046-2051

Gerlach G, Atema J, Kingsford MJ, Black KP, Miller-Sims V (2007) Smelling home can prevent dispersal of reef fish larvae. Proc Natl Acad Sci USA 104:858-863

Gherardi F, Atema J (2005) Effects of chemical context on shell investigation behavior in hermit crabs. J Exp Mar Biol Ecol 320:1-7

> Grol MGG, Nagelkerken I, Rypel AL, Layman CA (2011) Simple ecological trade-offs give rise to emergent crossecosystem distributions of a coral reef fish. Oecologia 165:79-88

> Hale R, Swearer SE, Downes BJ (2009) Separating natural responses from experimental artefacts: habitat selection by a diadromous fish species using odours from conspecifics and natural stream water. Oecologia 159: $679-687$ 
Hamner W, Jones M, Carleton J, Hauri I, Williams DM (1988) Zooplankton, planktivorous fish, and water currents on a windward reef face: Great Barrier Reef, Australia. Bull Mar Sci 42:459-479

- Hara TJ (1973) Olfactory responses to amino acids in rainbow trout, Salmo gairdneri. Comp Biochem Physiol A 44: 407-416

- Hara TJ (1975) Olfaction in fish. Prog Neurobiol 5:271-335

Holland RA, Thorup K, Gagliardo A, Bisson IA, Knecht E, Mizrahi D, Wikelski M (2009) Testing the role of sensory systems in the migratory heading of a songbird. J Exp Biol 212:4065-4071

> Huijbers CM, Mollee EM, Nagelkerken I (2008) Post-larval French grunts (Haemulon flavolineatum) distinguish between seagrass, mangrove and coral reef water: implications for recognition of potential nursery habitats. J Exp Mar Biol Ecol 357:134-139

> Huijbers CM, Nagelkerken I, Govers LL, van de Kerk M, Oldenburger JJ, de Brouwer JHF (2011) Habitat type and schooling interactively determine refuge-seeking behavior in a coral reef fish throughout ontogeny. Mar Ecol Prog Ser 437:241-251

> Huijbers CM, Nagelkerken I, Lössbroek PAC, Schulten IE, Siegenthaler A, Holderied MW, Simpson SD (2012) A test of the senses: fish select novel habitats by integrating multiple cues. Ecology 93:46-55

Igulu MM, Nagelkerken I, Fraaije R, van Hintum R, Ligtenberg H, Mgaya YD (2011) The potential role of visual cues for microhabitat selection during the early life phase of a coral reef fish (Lutjanus fulviflamma). J Exp Mar Biol Ecol 401:118-125

> Jenkins GP, Sutherland CR (1997) The influence of habitat structure on nearshore fish assemblages in a southern Australian embayment: colonisation and turnover rate of fishes associated with artificial macrophyte beds of varying physical structure. J Exp Mar Biol Ecol 218:103-125

Kimirei IA, Nagelkerken I, Griffioen B, Wagner C, Mgaya YD (2011) Ontogenetic habitat use by mangrove/seagrass-associated coral reef fishes shows flexibility in time and space. Estuar Coast Shelf Sci 92:47-58

> Kimirei IA, Nagelkerken I, Trommelen M, Blankers P and others (2013) What drives ontogenetic niche shifts of fishes in coral reef ecosystems? Ecosystems 16:783-796

Kingsford MJ, Leis JM, Shanks A, Lindeman KC, Morgan SG, Pineda J (2002) Sensory environments, larval abilities and local self-recruitment. Bull Mar Sci 70:309-340

Kirschvink JL, Gould JL (1981) Biogenic magnetite as a basis for magnetic field detection in animals. Biosystems 13:181-201

Kruitwagen G, Nagelkerken I, Lugendo BR, Mgaya YD, Wendelaar Bonga SE (2010) Importance of different carbon sources for macroinvertebrates and fishes of an interlinked mangrove-mudflat ecosystem (Tanzania). Estuar Coast Shelf Sci 88:464-472

> Lecchini D, Shima J, Banaigs B, Galzin R (2005) Larval sensory abilities and mechanisms of habitat selection of a coral reef fish during settlement. Oecologia 143:326-334

> Lecchini D, Planes S, Galzin R (2007) The influence of habitat characteristics and conspecifics on attraction and survival of coral reef fish juveniles. J Exp Mar Biol Ecol 341:85-90

Leis JM, Sweatman HPA, Reader SE (1996) What the pelagic stages of coral reef fishes are doing out in blue water: daytime field observations of larval behavioural capabilities. Mar Freshw Res 47:401-411
Leis JM, Carson-Ewart BM, Cato DH (2002) Sound detection in situ by the larvae of a coral-reef damselfish (Pomacentridae). Mar Ecol Prog Ser 232:259-268

> Lugendo BR, Nagelkerken I, van der Velde G, Mgaya YD (2006) The importance of mangroves, mud and sand flats, and seagrass beds as feeding areas for juvenile fishes in Chwaka Bay, Zanzibar: gut content and stable isotope analyses. J Fish Biol 69:1639-1661

Lugendo BR, de Groene A, Cornelissen I, Pronker A, Nagelkerken I, van der Velde G, Mgaya YD (2007) Spatial and temporal variation in fish community structure of a marine embayment in Zanzibar, Tanzania. Hydrobiologia 586:1-16

McCormick MI, Holmes TH (2006) Prey experience of predation influences mortality rates at settlement in a coral reef fish, Pomacentrus amboinensis. J Fish Biol 68: 969-974

McCormick MI, Kerrigan BA (1996) Predation and its influence on the condition of a newly settled tropical demersal fish. Mar Freshw Res 47:557-562

Milicich MJ, Doherty PJ (1994) Larval supply of coral-reef fish populations: magnitude and synchrony of replenishment to Lizard Island, Great Barrier Reef. Mar Ecol Prog Ser 110:121-134

> Montgomery JC, Jeffs A, Simpson SD, Meekan M, Tindle C (2006) Sound as an orientation cue for the pelagic larvae of reef fishes and decapod crustaceans. Adv Mar Biol 51: 143-196

Nagelkerken I (2009) Evaluation of nursery function of mangroves and seagrass beds for tropical decapods and reef fishes: patterns and underlying mechanisms. In: Nagelkerken I (ed) Ecological connectivity among tropical coastal ecosystems. Springer, Dordrecht, p 357-399

Nevitt GA (2008) Sensory ecology on the high seas: the odor world of the procellariiform seabirds. J Exp Biol 211: 1706-1713

Olsson M, Madsen T, Nordby J, Wapstra E, Ujvari B, Wittsell $\mathrm{H}$ (2003) Major histocompatibility complex and mate choice in sand lizards. Proc R Soc Lond B Biol Sci 270: 254-256

Peterson CH, Renaud PE (1989) Analysis of feeding preference experiments. Oecologia 80:82-86

> Pollen AA, Dobberfuhl AP, Scace J, Igulu MM, Renn SCP, Shumway CA, Hofmann HA (2007) Environmental complexity and social organization sculpt the brain in Lake Tanganyikan cichlid fish. Brain Behav Evol 70:21-39

Pollux BJA, Verberk WCEP, Dorenbosch M, Cocheret de la Morinière E, Nagelkerken I, van der Velde G (2007) Habitat selection during settlement of three Caribbean coral reef fishes: indications for directed settlement to seagrass beds and mangroves. Limnol Oceanogr 52: 903-907

Scapini F, Fallaci M, Mezzetti MC (1996) Orientation and migration in Talitrus saltator. Rev Chil Hist Nat 69: 553-563

> Shoji T, Yamamoto Y, Nishikawa D, Kurihara K, Ueda H (2003) Amino acids in stream water are essential for salmon homing migration. Fish Physiol Biochem 28: 249-251

> Sweatman H (1988) Field evidence that settling coral reef fish larvae detect resident fishes using dissolved chemical cues. J Exp Mar Biol Ecol 124:163-174

Tolimieri N, Haine O, Jeffs A, McCauley R, Montgomery J (2004) Directional orientation of pomacentrid larvae to ambient reef sound. Coral Reefs 23:184-191 
Toonen RJ, Tyre AJ (2007) If larvae were smart: a simple model for optimal settlement behavior of competent larvae. Mar Ecol Prog Ser 349:43-61

Wang Y, Bonynge G, Nugranad J, Traber $M$ and others (2003) Remote sensing of mangrove change along the Tanzania coast. Mar Geod 26:35-48

Ward AJW, Mehner T (2010) Multimodal mixed messages: the use of multiple cues allows greater accuracy in social recognition and predator detection decisions in the mosquitofish, Gambusia holbrooki. Behav Ecol 21:1315-1320

Waycott M, Duarte CM, Carruthers TJB, Orth RJ and others
(2009) Accelerating loss of seagrasses across the globe threatens coastal ecosystems. Proc Natl Acad Sci USA 106:12377-12381

Wehner R, Michel B, Antonsen P (1996) Visual navigation in insects: coupling of egocentric and geocentric information. J Exp Biol 199:129-140

Weldon AJ, Haddad NM (2005) The effects of patch shape on indigo buntings: evidence for an ecological trap. Ecology 86:1422-1431

Zollner PA, Lima SL (2005) Behavioral tradeoffs when dispersing across a patchy landscape. Oikos 108:219-230
Appendix 1. Table A1. Statistical summary results for all figures

\begin{tabular}{|c|c|c|c|c|}
\hline Figure & Test & Parameter & $\mathrm{df}$ & $\mathrm{p}$-value \\
\hline $4 \mathrm{a}$ & \multirow{7}{*}{$\begin{array}{l}\text { Paired } \\
\text { sample } \\
t \text {-test }\end{array}$} & $t(2.484)$ & 34 & 0.018 \\
\hline $4 \mathrm{~b}$ & & $t(2.686)$ & 22 & 0.007 \\
\hline $4 \mathrm{C}$ & & $t(2.260)$ & 34 & 0.030 \\
\hline $5 a$ & & $t(2.614)$ & 20 & 0.016 \\
\hline $5 b$ & & $t(5.587)$ & 23 & 0.001 \\
\hline $5 c$ & & $t(2.963)$ & 7 & 0.025 \\
\hline $5 d$ & & $t(8.677)$ & 13 & 0.001 \\
\hline $5 e$ & $\begin{array}{l}\text { Repeated mea- } \\
\text { sure ANOVA }\end{array}$ & $F(0.672)$ & $3 / 32$ & 0.570 \\
\hline $6 a$ & \multirow{11}{*}{$\begin{array}{l}\text { Paired } \\
\text { sample } \\
t \text {-test }\end{array}$} & $t(2.490)$ & 33 & 0.018 \\
\hline $6 b$ & & $t(-0.229)$ & 34 & 0.820 \\
\hline $6 c$ & & $t(2.553)$ & 23 & 0.018 \\
\hline $7 a$ & & $t(-1.198)$ & 34 & 0.239 \\
\hline $7 b$ & & $t(3.212)$ & 34 & 0.003 \\
\hline $7 \mathrm{C}$ & & $t(3.212)$ & 18 & 0.013 \\
\hline $7 d$ & & $t(2.553)$ & 14 & 0.030 \\
\hline $8 a$ & & $t(-0.352)$ & 26 & 0.727 \\
\hline $8 b$ & & $t(-2.544)$ & 30 & 0.012 \\
\hline A1a & & $t(-0.781)$ & 9 & 0.453 \\
\hline A1b & & $t(-0.825)$ & 9 & 0.432 \\
\hline
\end{tabular}

Editorial responsibility: Janet Ley, St. Petersburg, Florida, USA
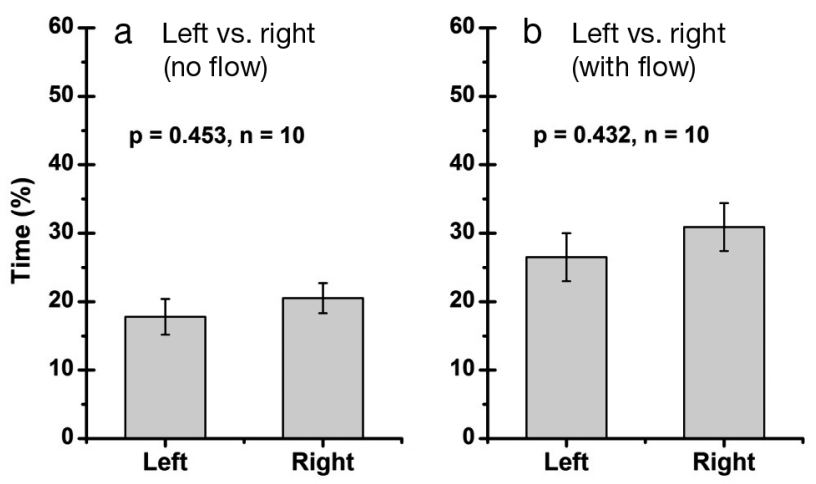

Fig. A1. Results from control experiments performed in the dual-choice aquaria showing mean percentage $( \pm \mathrm{SE})$ of time fish spent at left versus right sides of the aquarium when offered the same cue at both sides. (a) Both side-compartments held non-flowing neutral water without any cues. (b) Neutral water without cues flowed from both side compartments to the main compartment. p-values show results of paired $t$-tests and $\mathrm{n}=$ number of replicates

Submitted: March 22, 2013; Accepted: August 27, 2013

Proofs received from author(s): November 12, 2013 